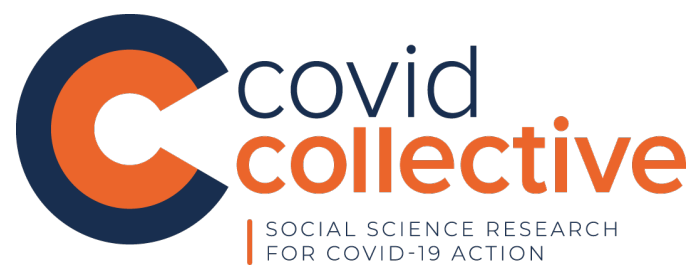

\section{Intersectionality and responses to Covid-19}

\author{
Jenny Birchall \\ Independent researcher \\ 22 March 2021
}

\section{Questions}

- What literature is there on the benefits, challenges, and opportunities of intersectional responses to socioeconomic impacts of Covid-19?

- Are there examples of policies or programmes that have taken an intersectional approach in selected Covid Collective countries? (Afghanistan, Bangladesh, Ghana, Iraq, Kenya, Malawi, Pakistan, Rwanda, South Sudan, Syria, Uganda, Yemen, Zambia and Zimbabwe)

\section{Contents}

1. Summary

2. What is intersectionality?

3. Intersectionality and Covid-19

4. Emerging good practice

5. References

The Covid Collective helpdesk service provides brief summaries of current research, evidence, and lessons learned. Helpdesk reports are not rigorous or systematic reviews; they are intended to provide an introduction to the most important evidence related to a research question. They draw on a rapid desk-based review of published literature and consultation with subject specialists.

This Helpdesk report was commissioned through the Covid Collective based at the Institute of Development Studies (IDS) and is funded by the UK Foreign Commonwealth and Development Office (FCDO) The Collective brings together the expertise of, UK and Southern based research partner organisations and offers a rapid social science research response to inform decision-making on some of the most pressing Covid-19 related development challenges. The views and opinions expressed do not necessarily reflect those of FCDO, the UK Government, or any other contributing organisation. For further information, please contact covidcollective@ids.ac.uk 


\section{Summary}

There is a small but growing body of literature that discusses the benefits, challenges and opportunities of intersectional responses to the socioeconomic impacts of the Covid-19 pandemic. There is a strong body of evidence pointing to the disproportionate impact of Covid-19 borne by women, who have suffered record job losses, been expected to take on even greater unpaid care burdens and home schooling responsibilities, and faced a "shadow pandemic" of violence against women and girls. However, gender inequalities cannot be discussed in isolation from other inequalities. Emerging literature stresses the importance of a Covid-19 recovery plan that addresses how gender intersects with class, race, disability, age, sexual orientation, geography, immigration status and religion or belief, and other factors such as employment, housing (and homelessness) and environmental and political stressors.

\section{Key findings}

- An intersectional approach reveals how the ongoing pandemic, and responses to it, affect social groups differently, highlighting how particular measures which are beneficial for certain groups may reinforce pre-existing situations of injustice for others. It allows identification of the groups most at direct and indirect risk from Covid-19 and its aftermath.

- Evidence is available to demonstrate the intersectional impacts of the pandemic, and the need for responses that recognise intersectionality, across a range of areas, including: gender-based violence; mental health; sexual and reproductive health and rights; livelihoods and social protection; and education.

- Over the last twelve months, guidance documents have begun to be published to support intersectional analysis of, and responses to the pandemic. These cover a range of issues including: data collection and disaggregation; contextual analysis; service planning and delivery; and representation in decision making and leadership. The majority of guidance around socioeconomic responses to the pandemic, however, still tends to focus on single areas of equality, such as gender, disability, or age, albeit with some acknowledgment of intersectional links with other areas.

- Examples of Covid-19 response policies and programmes with intersectional elements are beginning to be published. In the time available for this review, it was not possible to find published examples for all the Covid Collective countries. Therefore, some examples from other low- and middle-income countries have been included. It was also difficult to identify examples of initiatives that have been evaluated, given that many have had short timelines or are still in progress, so most of the examples do not include information on evaluated success and impact.

\section{What is intersectionality?}

The term intersectionality was coined in 1989 by Professor Kimberlé Crenshaw in a paper on "demarginalising the intersection of race and sex" (Crenshaw, 1989). The concept was first used in African-American feminist, disability and Marxist-feminist writing and has since become a commonly used term in thinking and practice around the nature of injustice and inequality (Horn, 2013, p. 29). There are now many different definitions of intersectionality, but a common understanding is that it provides a critical framework for understanding interlocking systems of oppression (Poteat, 2021, p. 91). 
Discussing intersectionality in the context of the Covid-19 pandemic, Hankivsky and Kapilashrami (2020) define intersectionality as a perspective that:

promotes an understanding of human beings as shaped by the interaction of different social locations, e.g. 'race'/ ethnicity, Indigeneity, gender, class, sexuality, geography, age, disability/ability, migration status, religion. These interactions occur within a context of connected systems and structures of power, e.g., law, policies, state governments, religious institutions, media. Through such processes, interdependent systemic bases of privilege and oppression derived from colonialism, imperialism, racism, homophobia, ableism and patriarchy are created (Hankivsky and Kapilashrami, 2020, p. 1).

Increasingly, work on gender equality and women and girls' rights is recognising the importance of taking an intersectional perspective. Intersectional gender analysis involves "analysing how gender power relations intersect with other social stratifiers to affect people's lives and create differences in needs and experiences. It also analyses how policies, services and programmes can help to address these differences" (TDR, 2020, module 1).

\section{Intersectionality and Covid-19}

\section{What evidence is available on intersectional perspectives on Covid-19?}

Evidence is now available to demonstrate differences in the primary health risks of Covid-19 on women, men, ethnic minorities, people with disabilities, older people and those working in frontline occupations. In addition, some work has been done to look at these risks with an intersectional lens, for example by looking at the gender and ethnic makeup of frontline workers, or by considering the specific barriers faced by older women in accessing healthcare in some contexts (Holmes, et al., 2020). There is also literature that discusses how these risks have been exacerbated by government policies both pre- and during the pandemic, particularly policies that create a "hostile environment" for particular ethnic minorities and migrant groups, deepening health inequalities in intersectional ways (Dona, 2021).

When looking at the socioeconomic impacts of the pandemic, there is a small but growing body of literature that discusses the need for an intersectional approach to the Covid-19 response. Several commentaries have been published highlighting the inaccuracy of the phrases "we're all in this together" or "Covid-19 is the great equaliser". This literature argues that Covid-19 in fact highlights and increases disparities in power (Bowleg, 2020; Lokot and Avakyan, 2020; Ramze Rezaee, 2020).

Looking at this through an intersectional lens "highlights how power and inequality are structured differently for groups, particularly historically oppressed groups, based on their varied interlocking demographics" (Bowleg, 2020, p. 917). Similarly, Hinz and Zubek (2020), in their argument for an intersectional feminist approach to the Covid-19 pandemic, say that such an approach "reveals how the ongoing pandemic, and the policy responses to it, affect social groups distinctively, and highlights how particular measures which are beneficial for certain groups may reinforce preexisting situations of injustice, notably in the case of overlapping and mutually reinforcing marginalisations produced by global and local power structures" (Hinz and Zubek, 2020). 
Dasgupta, et al. (2020) argue that intersectional analysis around Covid-19 "should not limit itself to the cumulative disadvantages and injustices posed by the pandemic for specific social groups, but also examine the historical inequalities, structural drivers, and damaged social contract that underlie state-society relationships" (Dasgupta, et al., 2020, p. 1).

Herbert and Marquette (2021), in their analysis of Covid-19, governance and conflict, note that pre-existing structural weaknesses such as underinvestment in health care and precarious work, mean that inequalities become more stark during a pandemic like Covid-19. They argue that because vulnerabilities and inequalities overlap and interconnect, serving to multiply disadvantage, there is a clear need to better understand intersectionality (Herbert and Marquette, 2021 , p. 11). However, this is not necessarily an easy task; the authors note that "one of the biggest challenges when it comes to discussions about building resilience and 'building back better' is a lack of political will for - or even interest in - supporting vulnerable populations" (Herbert and Marquette, 2021, p. viii).

Efforts to "build back better" are supported by a strong body of evidence pointing to the disproportionate impact of Covid-19 borne by women, who have suffered record job losses, been expected to take on even greater unpaid care burdens and home schooling responsibilities, and faced a "shadow pandemic" of violence against women and girls. This has resulted in a "rollback" of women and girls' rights across the globe (Birchall, 2020; Hinz and Zubeck, 2020; UN Women, 2020e). However, gender inequalities cannot be discussed in isolation from other inequalities. A growing collection of literature stresses the importance of a Covid-19 recovery plan that addresses the ways that gender intersects with class, race, disability, age, sexual orientation, geography, immigration status and religion or belief, and other factors such as employment, housing (and homelessness) and environmental and political stressors (Ramze Rezaee, 2020; Hankivsky and Kapilashrami, 2020; Poteat, 2021; Ryan and El-Ayadi, 2020; Lakam, 2020).

As some commentators note, when we think narrowly about Covid-19's impacts on "women" or "men", we risk homogenising otherwise diverse experiences and reducing analysis to simplistic messaging (Hankivsky and Kapilashrami, 2020, p. 1). A more nuanced approach is therefore needed. CARE and the International Rescue Committee (2020) note that intersectional gender analysis allows us to identify the key groups at direct and indirect risk from Covid-19. This includes "the specific vulnerabilities of older people and people with disabilities, as well as the threat of increased racism against people of specific ethnic groups erroneously associated with the virus" (Haneef and Kalyanpur, 2020, p. 2). It also highlights the situations of "social, sexual and gender minority groups", drawing attention to the vulnerabilities of particular groups such as older LGBTIQ people and sex workers (Haneef and Kalyanpur, 2020, p. 3).

Lokot and Avakyan (2020) posit an intersectional approach that goes further; rather than focusing only on the impact of the pandemic on the rights of "women and girls" or "the most vulnerable groups", they argue for an approach that recognises the power dynamics and the systemic nature of discrimination and inequality surrounding the lives of women and girls, and does not position them as perpetually vulnerable (Lokot and Avakyan, 2020, p. 42).

Some planning, analysis and action around gender inequalities and the response to Covid-19 has been critiqued for failing to take an intersectional lens. Outright Action International (2020, p. 16), in its study on the impact of the pandemic on LGBTIQ people, argues that we need to "widen the gender lens", citing the absence of the specific barriers to support that LGBTIQ people may 
be facing due to their sexual orientation, gender identity and expression in the Gender and Covid-19 Working Group's ${ }^{1}$ recommendations on a gender-inclusive pandemic response.

\section{What evidence is available to demonstrate the relevance of intersectional responses to Covid-19?}

There is a constantly expanding body of evidence on the socioeconomic impacts of the pandemic. The selection of literature included below either has an explicit focus on intersectionality, or discusses intersectional impacts and factors, for example by looking at gender and disability, gender and age, or gender identity and socioeconomic status. These examples highlight why an intersectional approach is valuable.

\section{Cross-cutting issues}

Holmes et al. (2020, p. 3), in their analysis of the impacts of the Covid-19 crisis on vulnerable groups, highlight a range of intersectional risks and impacts. These include:

- Increases in poverty, loss of jobs and livelihoods for: women working in the informal economy; migrant informal workers such as domestic workers (who are largely women); and low earning women and people with disabilities.

- Increases in the burden of unpaid care work for women looking after children with disabilities.

- Increases in violence, and social and protection risks for: women and girls with disabilities, women and girls who are refugees, asylum seekers or undocumented migrants; adolescent girls; and disadvantaged children.

Several studies have taken learning from previous global public health crises such as the Zika virus in Latin America and the Caribbean, SARS in Asia and Ebola in West Africa and the Democratic Republic of Congo, to demonstrate the ways that the Covid-19 pandemic is, and will, impact on particular groups. Ryan and El-Ayadi (2020) discuss the ways that women with "multiple or compounding vulnerabilities" are at greater risk of the longer-term impacts of Covid19 , such as lack of access to healthcare and the economic impacts of job losses, unpaid care burdens, and education dropout (Ryan and El-Ayadi, 2020, p. 1406). They argue for the importance of intersectional approaches to understand the situations of women and girls in lower-resourced settings globally, including those in migration camps and detention centres, urban slums and conflict-affected areas, and those who are homeless (Ryan and El-Ayadi, 2020, p. 1407).

Rosser et al. (2021) also argue that the socioeconomic consequences of these previous crises fell disproportionately on more vulnerable members of society, including women and gender minorities. The authors argue that a data-driven response to Covid-19 is needed, one that includes analysis of intersectional disaggregated data, in order to demonstrate how the Covid-19 pandemic is impacting groups differently, in order to facilitate appropriate social, economic, and health protections and responses (Rosser, et al., 2021, p. 2). An intersectional approach is

\footnotetext{
${ }^{1}$ The Gender and Covid-19 Working Group is a global group of researchers, health practitioners, policy actors and advocates who share resources and expertise on topics related to gender equity, women's empowerment, human rights and Covid-19. https://www.genderandcovid-19.org/gender-working-group-page/
} 
particularly important in understanding socioeconomic impacts across six priority areas:

\section{Gender-based violence (GBV)}

A significant body of evidence exists to demonstrate the "shadow pandemic" of violence against women and girls during the Covid-19 crisis (UNDP, 2020; UN Women, 2020f), but an intersectional approach can also reveal the high rates of GBV experienced by particular groups of women and girls, and by LGBTQI people (Rosser et al., 2021, p. 3)

\section{Mental health}

While it is increasingly recognised that the pandemic is having far reaching mental health impacts, intersectional analysis highlights the groups at greater risk, including: women overburdened by balancing work, home, and care activities; children, adolescents and older adults struggling with the effects of social isolation; individuals with disabilities and pre-existing mental health conditions; the LGBTQI community; and frontline health workers (Rosser et al., 2021, p. 4)

\section{Sexual and reproductive health (SRH)}

As health resources during the pandemic are directed away from routine services and towards emergency services, an intersectional approach can demonstrate which groups are most negatively impacted. Women and girls of reproductive age from the most marginalised populations are likely to face significant obstacles to accessing SRH services (Rosser et al., 2021, p. 4).

\section{Economic and work-related concerns}

An intersectional approach allows consideration of those most economically vulnerable during and after the pandemic, including: workers without social protection in the event of unemployment, such as part time, informal sector and self-employed workers; migrant workers; racial and ethnic minorities; and women and girls who are more likely to be working in the most adversely affected sectors such as health and social care and retail, and to be undertaking unpaid care work. It also highlights how women and girls in lower income settings will be disproportionately impacted by the consequences of the economic fallout, such as food insecurity and child, early and forced marriage (Rosser et al., 2021, p. 4).

\section{Education}

The Covid-19 pandemic has disrupted education across the globe. Taking an intersectional approach to the effects of the pandemic on children and adolescents' education reveals the disproportionate negative impact on girls, refugees, learners with special educational needs, and students from resource poor and rural areas (Rosser et al., 2021, p. 7).

\section{Representation and valuing diverse voices}

Public health interventions will not succeed without meaningful participation for diverse communities. It is essential therefore, to take an intersectional approach, increasing representation of minorities in local, national and health governance (Rosser et al., 2021, p. 6).

One study looking at the response to Covid-19 in south Rajasthan, India, concluded that the absence of analysis and research taking an intersectional perspective on the implications of Covid-19 has meant that, despite response mechanisms being in place, several forms of deprivation, challenges and barriers are continuing to affect the lives of women from marginalised communities (Dutta, et al., 2020, p. 1). In rural communities in south Rajasthan, a 
combination of migration, geographical remoteness, low female literacy rates, high numbers of women working in unskilled labour, and high rates of malnourishment, has meant that marginalised women from Adivasi communities have "aftershocks" to the pandemic that have increased inequities that cut across class, caste and region (Dutta, et al., 2020, p. 2).

There are also studies focusing on the impact of the pandemic on particular intersectional identities and inequalities such as gender and disability, or gender and sexuality. Several recently published studies and papers highlight the impact of the pandemic on women and girls with disabilities, and the ways that the Covid-19 crisis has exacerbated the underlying structural inequalities faced, as barriers such as physical accessibility, affordability of healthcare, and discriminatory laws and stigma are heightened (Ito et al., 2020, Efange and Woodroofe, 2020).

In a study on the pandemic's negative impact on LGBTIQ people, Dasgupta et al. (2020) cite examples such as: gender-based quarantine measures in Peru, Colombia and Panama, which are most challenging for those who do not fit into binaries; increases in gender-based violence (GBV) targeted at LGBTIQ communities in Latin America; and increased transphobia and barriers to HIV treatment for trans people in India (Dasgupta, et al., 2020, p. 3).

\section{Sexual and reproductive health and rights}

The area of sexual and reproductive health and rights (SRHR) is one of those where, emerging evidence shows, an intersectional approach is particularly important (Dasgupta, et al., 2020; Lokot and Avakyan, 2020, Nazneen and Araujo, 2020). Pre-pandemic, SRHRs were already being suppressed by many governments, particularly for specific populations such as LGBTIQ people and ethnic minorities (McEwen, 2020). Increasing evidence is available demonstrating the ways that SRHR have been further denied and disrupted during the pandemic, particularly for groups such as adolescent girls, women with disabilities, LGBTIQ people, sex workers and people living with HIV (Landis, et al., 2020; Ito, et al., 2020; Dasgupta, et al., 2020; Gichuna, et al., 2020; Kimani, et al., 2020). As Nazneen and Araujo (2020) point out, women and girls in refugee camps and urban slums, who are experiencing multiple forms of disadvantage because of poverty, racial, ethnic and class inequalities among others, face particular barriers to SRHR (2020, p. 6).

Analyses conducted by CARE International assessing the impact of Covid-19 across several countries including Bangladesh, Nigeria and Ethiopia suggest that adolescent girls are facing particular barriers in accessing SRH services, due to a mixture of pre-existing disparities in access and Covid-19 related challenges unique to adolescent girls (Landis, et al., 2020, p. 10). When uptake of services began to rise after the first wave of lockdowns ended, this increase was slower for adolescent girls than for adult women. In addition, girls living in remote regions or fragile and conflict-affected contexts were facing heightened challenges (Landis, et al., 2020, p. 11).

Evidence also highlights a higher negative impact on the SRHR of poorer women and girls who are no longer able to access the public health services that have been overwhelmed by the pandemic. The economic barriers they face in accessing private, often unregulated health services, mean they are being pushed further into poverty and denied SRHR (Dasgupta, et al., 2020, p. 3). 


\section{Gender-based violence}

A number of studies support the proposal that the "shadow pandemic" of violence against women and girls needs to be viewed through an intersectional lens. UN Women has noted the importance of taking gender-differentiated actions to support women and girls experiencing heightened sexual and domestic violence as a result of the pandemic; stating that these actions should recognise the specific situations of women and girls with disabilities and those caring for dependents with disabilities (UN Women, 2020a, p. 1).

While one literature review conducted for the GBV AoR helpdesk in 2020 did not find any studies specifically looking at the intersection between disability and gender-based violence during the Covid-19 pandemic, it noted that available evidence suggests that women and girls with disabilities and female carers are likely to be facing a set of new barriers in accessing GBV programmes and services during the pandemic. These include: disrupted social services and assistance; reduced financial resources; and infection risk at health and women's centres (Pearce, 2020, p. 4).

There is also a body of literature looking at the specific experiences of adolescent girls and GBV during the pandemic. Drawing on learning from previous public health crises such as Ebola, this literature argues that adolescent girls face an increased risk of exposure to harm during the pandemic, whether through violence in the home, sexual exploitation and abuse, online harm, exposure to child, early and forced marriage, and barriers in accessing support (Landis, et al., 2020; Plan International UK, 2020).

Several studies point to the high levels of violence that were experienced by LGBTIQ people prepandemic, with this vulnerability increased by intersectional factors such as race, ethnicity, gender and socioeconomic status (Outright Action International, 2020). The Covid-19 pandemic has only intensified this situation, with LGBTIQ people facing isolation and abuse in lockdown situations (Hinz and Zubek, 2020; Outright Action International, 2020).

Finally, evidence shows that migrant, refugee and internally displaced women and girls have been at risk of heightened levels of GBV during the pandemic, as support services were disrupted, care burdens increased, and quarantine and lockdown measures in camps and settlements isolated survivors of violence and abuse (Banik et al., 2020; Plan International UK, 2020; ISCG Gender Hub, 2020).

\section{Livelihoods and social protection}

Evidence suggests that while governments worldwide have introduced relatively untargeted labour market policies and social protection programmes designed to respond to the Covid-19 pandemic and its economic impacts (ILO, 2021; Itcovitz et al., 2020; Gentilini et al., 2020), there are not many tailored government or donor policies and measures in place to protect or support specific groups such as women working in informal sectors (Hearle and Chaturvedi, 2020, p. 1). This is despite evidence to show that vulnerable and marginalised groups, including women with disabilities, women affected by HIV, and women from ethnic minorities, were already, prepandemic, having great difficulties accessing support (Lind, Roelen and Sabates-Wheeler, 2020, p. 15).

Several studies therefore highlight the importance of considering the socioeconomic impact of the pandemic not only on groups of workers such as women, people with disabilities, migrant 
workers, informal sector and self-employed workers, but also the intersections between these groups. As Nazneen and Araujo (2020) point out, the economic impact of the pandemic is greater for women in the informal sector and in agriculture, women migrant workers and femaleheaded households than it is for women in formal sector work (Nazneen and Araujo, 2020, p. 7).

Ruwisi (2020) discusses the example of women entrepreneurs and day traders in Zimbabwe, whose livelihoods depend on crossing borders to acquire and sell goods, and who have been placed in a particularly precarious economic situation by restrictions on movement during the pandemic. Hinz and Zubek (2020) consider the situations of female migrant workers across regions, who have experienced severe economic consequences from the pandemic, due to their high representation in the domestic and care sectors, and the impact of Covid-19 travel restrictions which prevent them from returning to their countries of origin.

There is also literature noting the particular vulnerabilities of LGBTIQ groups to the economic impacts of the pandemic (Outright Action International, 2020; Banerjee and Nair, 2020), given their overrepresentation in informal sectors. Some studies indicate that trans women in particular are experiencing disproportionate loss of livelihoods and food insecurity (Ahlenback, 2020; Outright Action International, 2020).

While there is agreement in the literature that social protection is key to addressing the economic impacts of Covid-19 (Banks, et al., 2021), some studies have highlighted problems with accessibility and applicability for particular groups of beneficiaries. Barca, et al. (2020) discuss the barriers in place in accessing programmes for women and girls with disabilities, including obtaining official documentation for programme registration, low confidence, low levels of literacy, low access to and ability to use digital platforms, mobility constraints (2020, p. 4).

Evidence on the opportunities around social protection for older people during and after the pandemic highlights the increased economic and social vulnerabilities of older people with disabilities, older women and older people caring for grandchildren or other family members (Juergens and Galvani, 2020, p. 5). However, globally there have only been minimal adaptations made to old age pensions as part of Covid-19 responses. Furthermore, research also highlights the barriers that older people are facing in accessing Covid-19 emergency social protection programmes, which have not been designed or implemented with the needs of specific groups in mind. In particular, older women are facing difficulties accessing programmes due to lower literacy levels, language barriers and less access to technology (Juergens and Galvani, 2020, pp. 8-9).

\section{Education}

Evidence also highlights the intersectional nature of the impacts of the Covid-19 pandemic on children and young people's education. Several studies highlight the disproportionate impact of school closures on girls, both during and after lockdowns. Girls' heavy workloads at home and limited access to technology and the internet mean that they are less likely to access remote learning. In the longer term, the economic impact of the pandemic may mean that families struggling financially are more likely to remove girls from schools than boys, and once out of school, girls face increased risks from GBV, child, early and forced marriage, trafficking and child labour (Landis, et al., 2020, Plan International UK, 2020). Internally displaced and refugee girls are a particularly at-risk group (ISCG Gender Hub, 2020). 
There is also literature about children with special educational needs and disabilities and Covid19 responses. As one study of the impact of the pandemic on people with disabilities in the UK highlighted, children with special educational needs are more likely to live in poverty and less likely to have access to technologies, both of which have been linked to less intensive home learning during the pandemic (Shakespeare et al., 2021, p. 21-22). Taking an intersectional approach to education during and post Covid-19 also highlights the situations of children in rural areas, in areas affected by conflict and insecurity, and those engaged in child labour (Human Rights Watch, 2020).

\section{Evidence on intersectional issues in Covid Collective countries}

For most of the selected Covid Collective countries ${ }^{2}$ it is possible to find published analyses around the gendered impact of the Covid-19 pandemic, or in some cases, the impact of the pandemic on people with disabilities. Some analyses went further and included intersectional impacts too. These are included below.

A rapid assessment of the gender-differentiated impacts of Covid-19 in Afghanistan conducted by UN Women, the International Rescue Committee and Roshan (2020) found that:

- Internally displaced women are disproportionately experiencing Covid-related impacts to their mental and emotional health

- Internally displaced and returnee women are bearing a higher burden of unpaid domestic care as a result of the pandemic

- Women IDPs are facing heightened problems around compromised water sources

A rapid gender analysis carried out by UN Women in Bangladesh used an intersectional lens to identify the following groups of women and girls deemed more vulnerable to the impacts of the pandemic. These included:

- Women headed households

- Women and girls with disabilities

- Adolescent girls

- Elderly women

- Indigenous women and girls

- Women migrant workers

- Women ready-made garment workers

- Women domestic workers and day labourers

- Trans women

- Female sex workers (UN Women, 2020c, pp. 13-15)

Another gender analysis in Bangladesh, looking specifically at Rohingya refugee communities (ISCG Gender Hub, 2020), reported a range of intersectional impacts of the pandemic, with refugee status combining with gender, age and disability in a number of ways, including:

\footnotetext{
2 Those selected are: Afghanistan, Bangladesh, Ghana, Iraq, Kenya, Malawi, Pakistan, Rwanda, South Sudan, Syria, Uganda, Yemen, Zambia and Zimbabwe
} 
- GBV is increasing, including intimate partner violence, polygamy, transphobic violence, and violence against female sex workers

- There is an increase in forced/child marriage and a halt in education. Pre-existing gender bias for boys' education is likely to be exacerbating with new schooling arrangements

- Single mothers, households headed by people with disabilities, pregnant and lactating women, elderly people and children face overwhelming difficulties accessing food

- Difficulty accessing WASH services has increased. Women and girls face issues of overcrowding, lack of privacy and harassment when using latrines, as well as shortages of menstrual hygiene products

- There is an increase in mental health issues, sense of insecurity and stress across the board, and in particular with men and boys (ISCG Gender Hub, 2020 pp. 6-7)

Gender analysis of the impact of the Covid-19 pandemic in Pakistan (Tariq and Bibler, 2020) found that:

- Women's political and electoral participation has been restricted; this is particularly the case for women with disabilities, young women and trans women

- There will be enormous economic consequences for women garment and textile workers, domestic workers and home-based workers, as well as women with disabilities and trans women who are largely working in unregulated sectors

- Pressure to drop out of school to care for siblings and support their households financially could widen the gap between girls' and boys' school enrolment, bringing longer term impacts on young women's participation in the workforce

A rapid gender analysis of Covid-19 in South Sudan noted the importance of the national response to be "grounded in a strong knowledge of gender dynamics, gender relations, sex and age disaggregated data that takes into account the differing experiences of all vulnerable groups (IDP women and children, disabled women, women and children in refugee camps)"

(Government of the Republic of South Sudan, 2020, p. 3).

A UN women brief looking at priorities for gender equality in Yemen's Covid-19 response notes the importance of considering the needs of particularly vulnerable groups of women and girls, such as GBV survivors, displaced women and girls, older women, women with disabilities and women detainees (UN Women 2020d, p. 1).

\section{Emerging good practice}

\section{Recommendations and guidance to support an intersectional response to Covid-19}

As discussions around intersectionality and Covid-19 have grown during the last year, a number of guidance documents have been published in order to support intersectional analysis of, and responses to the pandemic. Those identified in the time available for this review are summarised below. 


\section{Cross-cutting intersectional issues}

Hankivsky and Kapilashrami (2020, p. 4) in their intersectional analysis of the Covid-19 outbreak and response, make a number of broad recommendations:

- Move beyond sex disaggregated data to include age, health status, disability, occupation, socioeconomic status, migratory status and geographic location.

- Collect data from diverse sources

- Contextualise data to include socioeconomic and political context

- Undertake an intersectional analysis of national and international responses to Covid-19

- Broaden bailout and stimulus packages to prioritise those most at risk

- Make policy responses cross-sectoral

- Move beyond a deficit model and prioritise engagement among affected populations

- Commit to leadership diversity

Ryan and El-Ayadi (2020, p. 1408), in their call for a gender-responsive, intersectional approach to address Covid-19, make recommendations around pandemic containment, as well as mitigation of its immediate and long-term consequences. These include:

- Innovate service delivery rather than interrupt support services, such as transitioning to mHealth provision for critical services like essential sexual and reproductive health care and case management for gender-based violence

- Collect diverse data from multiple sources, including governments, but also practitioners and civil society

- Contextualise data within systems of power, including how social forces influence one's social location within household, community and the wider health system, as well as how Covid-19 is exacerbated by globalisation, capitalism, urbanisation, war, conflict, climate change, racism and xenophobia

- Support disaggregated surveillance, research, and programming through gender-based budgeting.

- Mainstream intersectionality through research design, programme delivery, and evaluation

- Foster community participation and include the lived experiences of women who live at the intersections of oppressions and inequalities

- Utilise an assets-based approach in programmes and capitalise on existing community strengths and resources

- Ensure remote education reaches girls, not just boys, whose schooling may be challenged by concurrent domestic labour or caregiving responsibilities

- Provide Covid-19 guidance on gender mainstreaming by global public health organisations like the WHO to encourage assessment of policy implications based on gender in all areas and at multiple levels

- Ensure gender parity in Covid-19 working groups and support women representing diverse experiences in leadership positions (across government, industry, non-profit sectors) to promote gender-informed decision making 
The Gender and Covid-19 project ${ }^{3}$ has developed a gender-responsive pandemic plan, which takes into consideration the intersectional needs of women, men, and gender minorities in planning, data collection, response and recovery. The plan discusses the intersectional gender dynamics of six priority areas: gender-based violence; sexual and reproductive health services; mental health; economic and work-related concerns, including livelihoods, the informal sector and unpaid care work; representation and valuing diverse voices; and education (Rosser, et al., 2021). The plan includes a framework with key activities, outcomes and indicators for each priority area.

Guidance produced by the Risk Communication and Community Engagement Working Group on Covid-19 Preparedness and Response in Asia and the Pacific has sections on children, people with disabilities, women and girls, pregnant women, people living with HIV, gender-based violence survivors, refugees and migrants, the elderly, people living in existing humanitarian emergencies, people with pre-existing medical conditions, sexual and gender minorities, and ethnic minorities (RCCE Working Group, 2020).

\section{Disability and gender}

In April 2020, a statement on rights at the intersection of gender and disability during Covid-19 was developed by the organisation Women Enabled International and partners (2020a). The statement is intended to ensure that decision makers working on Covid-19 responses have the tools they need to ensure that responses are inclusive of women, girls, non-binary persons, and gender non-conforming persons with disabilities. After conducting a global survey in March and April 2020, Women Enabled International (2020b) published a further set of recommendations for state actors around gender, disability and responses to the pandemic.

The key components of the statement are:

- Gender-based violence against women, girls, non-binary, and gender non-conforming persons with disabilities must be specifically targeted and prevented during the crisis, and services related to addressing and preventing gender-based violence are essential services

- States must ensure the basic needs of all during this crisis and maintain access to income and education

- There can be no rationing of healthcare, including life-saving healthcare, that excludes or deprioritises people based on disability, gender, or age, and all people must have access to Covid-19 testing and treatment without discrimination

- Sexual and reproductive health services are essential services and must be provided free from discrimination

- Support services for persons with disabilities are essential services and must be maintained during this crisis

\footnotetext{
${ }^{3}$ The Gender and Covid-19 project is funded by the Canadian Institute of Health Research and is designed to brings together academics from around the world to identify and document the gendered dynamics of Covid-19 and gaps in preparedness and response: https://www.genderandcovid-19.org
} 
- Women, girls, non-binary, and gender non-conforming persons with disabilities must be included in response efforts related to Covid-19 (Women Enabled International, 2020a)

Further recommendations include:

- Undertake particular efforts to reach women, girls, non-binary, trans, and gender nonconforming persons with disabilities with social protection measures, including through campaigns that provide information in a variety of accessible formats.

- Classify disability-related support services, sexual and reproductive health services, and gender-based violence services as essential services during Covid-19 lockdowns, stayin-place orders, or other restrictions on movement.

- Continue or initiate efforts to tackle stereotypes and stigma about gender and/or disability, as a means of protecting individuals from violence during this crisis and ensuring they get the community supports and healthcare they need (Women Enabled International, 2020b, p. 18)

Women Enabled International is currently preparing an update document on the statement, as well as a collection of good practice, in partnership with UNFPA.

The Inter-Agency Working Group on Disability Inclusive Covid-19 Response and Recovery has produced a checklist for planning a disability-inclusive socioeconomic response and recovery. The checklist recommends that:

- Plans and budgets should take into consideration the specific needs of women and girls with disabilities

- Official data should be disaggregated by disability (as well as disability type), sex and age, urban vs. rural residence, and other status (IAWG on Disability Inclusive Response and Recovery, 2020a, p. 1-2)

Other guidance documents containing recommendations relating to disability and gender include the International Disability Alliance's (2020) recommendations for a disability-inclusive Covid-19 response, and the United Nations (2020) policy brief on a disability-inclusive response to Covid19.

In a GBV AoR helpdesk report looking at disability and GBV programmes during Covid-19, Pearce (2020, p. 4) puts forward a number of recommendations relating to disability inclusion in programming during the pandemic. These include:

- Establish partnerships with organisations of persons with disabilities, particularly organisations of women and girls with disabilities, and caregiver groups. Consult with these organisations on the potential barriers and appropriate strategies for accessing GBV services during the Covid-19 pandemic

- Support sensitisation and training of GBV staff on disability

- GBV practitioners should adopt adapted and remote approaches when responding to the GBV-related needs of persons with disabilities and their caregivers during the Covid-19 pandemic

- Establish a plan for continuation of support services and personal assistance 
- Disseminate information in accessible formats through disability service providers, organisations of women with disabilities and health facilities

- Strengthen the capacity of organisations of persons with disabilities and disability service providers on GBV

\section{Education}

Drawing on learning from previous public health crises such as Ebola, the World Bank's Gender Innovations Lab, which focuses on Sub-Saharan Africa, has developed a number of recommendations that, if implemented, could help keep more adolescent girls in school during and post-pandemic. These include adapting adolescent girl programmes focused on mentoring, support networks, and providing vocational and life skills training to a virtual format. Learning from pre-Covid programmes in Uganda, Liberia, Malawi, South Sudan and Sierra Leone demonstrates how such programmes can not only help keep girls in school during emergencies, but also foster resilience and expand girls' economic opportunities, mitigating the impacts of future crises (Gender Innovation Lab, 2020, p. 6).

Recommendations on teacher and learner wellbeing during the pandemic developed by the KIX Observatory on Covid-19 responses (2020, p. 13), include:

- Collection of disaggregated data related to the impact of Covid-19 on learners' protection risks, by age, sex, gender, disability, and other gender-related indicators should be undertaken

- Develop gender-responsive Covid-19 education response plans reflecting lived realities of girls with disabilities, in rescue and humanitarian settings and other learners at basic levels of education

\section{Livelihoods and social protection}

In a position paper developed for Irish Aid on "building back better" from the pandemic, Nazneen and Araujo (2020) recommend that efforts to reduce the economic impact of Covid-19 should support the provision and expansion of interventions that give targeted relief for women and girls belonging to the most disadvantaged groups. These include, among others: female-headed households, adolescent girls, elderly women, refugee women, women in informal sector work/migrant women in precarious employment, and women and girls with disabilities (Nazneen and Araujo, 2020, p. 21).

One briefing produced by the WOW (Work and Opportunities for Women) helpdesk for the UK government, contains a range of short, medium and long-term recommendations on supporting women informal workers as part of the response to Covid-19 (Hearle and Chaturvedi, 2020, p. 2). These include:

- Work with governments to ensure that policies and interventions aimed at response and recovery are informed by intersectional analysis and rapid gender assessments of the impacts of Covid-19 and are context specific and targeted.

- Influence governments to implement social protection measures that have universal/near universal or categorical targeting, considering how the type of benefit will support existing/remaining informal livelihoods. 
- Ensure women informal workers and representative organisations have a voice in decision making, leadership and participation in Covid-19 responses and plans at local/municipal, regional and national levels.

- Advocate and ensure that the urgent and special needs of women informal workers with disabilities impacted by Covid-19 should be fully integrated into government response measures.

- Adjustments and expansion in existing social and labour protection systems should be gender responsive and inclusive to ensure that all workers, regardless of their contractual status, are afforded adequate labour and social protection.

- Develop the unpaid and paid caregiving economy and infrastructure. Support quality and affordable care services including childcare to both create decent jobs and enable primarily women to return to work.

- Provide targeted measures to help self-employed women restart their businesses.

The World Bank's Gender Innovation Lab has come up with a number of recommendations designed to support women entrepreneurs in Sub-Saharan Africa both during the pandemic and as part of economic recovery (Gender Innovation Lab, 2020, p. 4). These include:

- Issuing credit and meso-financing to provide liquidity to women-owned firms in times of crisis

- Helping women-owned firms to formalise through small incentives in order to boost their access to financial services

- Offering personal initiative training, which teaches women entrepreneurs to be proactive and demonstrate perseverance and may help them to bounce back from the economic impacts of Covid-19

- Providing coaching and training on sector choice to guide women who are starting new self-employment livelihoods during the recovery phase

The Gender Innovation Lab has also produced recommendations designed to support women farmers' livelihoods in Sub-Saharan Africa as part of the Covid-19 response. These include:

- Providing productive inputs (such as livestock, fertiliser, seeds) directly to women farmers

- Encouraging farming couples to create joint action plans to help include women in highervalue agricultural activities, offering an opportunity to promote market inclusion in the aftermath of the crisis

- Developing digital extension services to be used when traditional agricultural extension programmes are curtailed to limit person-to-person contact (Gender Innovation Lab, 2020, p. 5)

Guidance on disability-inclusive social protection responses to the Covid-19 crisis produced by the UN Partnership on the Rights of Persons with Disabilities recognises that the inequalities faced by people with disabilities are heightened for women and girls with disabilities, and recommends that social protection responses should "include needs assessments of persons with disabilities, with attention to children, women and girls with disabilities, persons with high support requirements and older persons" (UNPRPD, 2020b, p. 2). 
Barca et al. (2021) discuss how information systems for social protection programmes could be more inclusive for women and people with disabilities during and post-pandemic. They note that while the most important factor affecting exclusion or inclusion in programmes is "the policy decision regarding the range of social protection benefits and services on offer and the design of the eligibility criteria and qualifying conditions for these", information systems can still play an important role in increasing inclusivity. Their examples of using these systems in gender and disability-inclusive ways include:

- Categorical targeting: using the disability status or specific family situation of women (e.g. single female head of household) as a criteria for eligibility

- Giving increased scoring/weight to women, persons with disabilities and other vulnerable categories when profiling needs in data-driven approaches

- Better addressing intersectionalities: i.e. how gender and disability intersects with other social identifiers, such as age, race, ethnic/migrant status etc.

- Tailoring the overall benefit/service package and transfer amounts to the additional (multiple and varied) needs of women and persons with disabilities (Barca, et al., 2021, p.19)

\section{Examples of programmes and policies that take an intersectional approach to the Covid-19 response}

While examples of potential "good practice" policies and programmes were identified for some of the Covid Collective countries, it was not possible to find published examples for all of the countries in the time available for this review. The examples below therefore include learning from other low- and middle-income countries too. It was also difficult to identify examples of initiatives that have been evaluated, given that many have had short timelines or are still in progress, so the majority of the examples do not include information on evaluated success and impact.

\section{IOM consultation with organisations of persons with disabilities in South Sudan}

At the outset of the Covid-19 crisis, the International Organisation for Migration (IOM) consulted with people with disabilities located in both internally displaced and host community settings to design a more disability-inclusive approach to its response. One of the objectives of the consultations was to understand and respond to the potential disproportionate impact of the crisis on women, children and older persons with disabilities. When organising the consultation, the IOM team tried to ensure equal participation of women with disabilities, but this was not possible due to the low representation of women in the organisations consulted. It is not clear whether women's organisations were approached as part of the consultation (IAWG on Disability Inclusive Response and Recovery, 2020b, p. 3).

\section{Partnership work in Latin America and the Caribbean to support displaced people with disabilities}

UNHCR worked with the Latin American Network of Non-Governmental Organizations of Persons with Disabilities and their Families (RIADIS) to conduct a regional assessment of the situation of refugees, migrants and displaced persons with disabilities, and produce information materials to raise awareness on the situations of displaced people with disabilities during the COVID-19 pandemic (IAWG on Disability Inclusive Response and Recovery, 2020b, p. 4). 


\section{A social safety net programme for refugees with disabilities in the West Bank}

After undertaking a needs assessment of refugees with disabilities living in camps in the West Bank, the United Nations Relief and Works Agency for Palestine Refugees in the Near East (UNRWA) organised home delivery of important items in order to mitigate the increased economic hardship they were facing. A social safety net programme, targeting the poorest families in the West Bank, was brought forward to help refugees with disabilities to buy basic items and pay bills. Deferral of monthly loan repayments was also offered. These activities allowed refugees with disabilities and their families to meet their basic needs and comply with Covid-19 prevention guidance and restrictions (IAWG on Disability Inclusive Response and Recovery, 2020b, p. 5).

\section{Women's empowerment hubs for refugee and internally displaced women}

In South Sudan, Uganda, Bangladesh and Jordan, UN Women has set up "women's empowerment hubs" to provide integrated support to refugee and internally displaced women during the pandemic. In the hubs, women can receive GBV awareness training and counselling, and they can learn new livelihoods, income generation and leadership skills (UN Women, 2020b, p. 12).

\section{Targeted social protection measures for vulnerable groups}

An UNPRPD overview of specific social protection measures for persons with disabilities and their families in response to Covid-19 found that the key measures being implemented globally are cash transfers, in-kind support, and adaptation of delivery mechanisms in relation to Covid19 risks and lockdown restrictions. Some of these measures appear to have intersectional dimensions. For example, in Algeria, Egypt, Norway, Latvia and Romania, paid leave for parents or family members of persons with disabilities has been extended. In South Sudan, direct cash transfers are being directed at a range of vulnerable groups, including women who are pregnant or breastfeeding (UNPRPD, 2020a).

\section{Girl-informed assessment, planning and communication in Malawi, Ethiopia and Rwanda}

In Malawi, CARE is working with youth leaders and health workers to pilot a digital version of its Community Score Card, focusing on the situation of adolescents in the midst of the Covid-19 pandemic. Learning from this pilot will be used to inform similar efforts in other countries in order to empower adolescent girls to hold service providers accountable for their health and rights (Landis, et al., 2020, p 16).

In Ethiopia, when health activities for married adolescents were closed as a result of Covid-19, CARE sought the advice of young female group leaders during response planning to identify appropriate alternate locations for the distribution of hygiene materials. Adolescent leaders also advised CARE staff on the needs of girls in the community as a result of Covid-19, and potential ways in which programming could be adapted in response (Landis, et al., 2020, p 16).

In Rwanda, CARE engaged in mass media communication strategies, including adolescentfocused, age-appropriate radio talk shows named "Ask Auntie," after the role of village aunts as sources of advice for girls. CARE staff also sent text messages to girls with essential information on GBV prevention and response, health services, and economic empowerment issues (Landis, et al., 2020, p 18). 


\section{Supporting vulnerable groups of girls to remain in education during Covid-19 in Afghanistan, Jordan and Malawi}

In Afghanistan, the Steps Towards Afghan Girls' Educational Success II programme, implemented by the Aga Khan Foundation, Save the Children UK, CARE, Catholic Relief Services, Aga Khan Education Services and AEPO, has focused during the pandemic on the safe distribution of printed materials during school closures along with gender norm programming prioritising girls' education in the home space. Teachers liaised with parents and set up weekly check-in calls with girls to support their learning and help them study challenging topics. Additional support to girls with disabilities promoted access to remote learning material and ensured that adapted approaches were inclusive (UNICEF, 2021, p. 21).

In Jordan, CARE has provided conditional cash assistance to families of girls at risk of dropping out of school due to the pandemic. Families receive financial support in exchange for ensuring that girls remain in school. Through this initiative, families are provided with 70 Jordanian Dinar (US \$100) per month to help cover essential expenses, as well training on protection issues and referrals to necessary services (Landis, et al., 2020, p 26).

In Malawi, the Jesuit Refugee Service, UNHCR, Plan International and Yetu Radio have worked together to target refugee and asylum-seeking girls aged 10-25 years living in and around the Dzaleka refugee camp, with the aim of providing continuity of learning, health, protection, and overall wellbeing for girls during Covid-19 school closures. Teachers were trained to use different modes of distance learning, including radio, social media, and online platforms. There were listening sessions with girls to understand their unique challenges, needs, and risks, such as poverty, child, early and forced marriage, unpaid care burdens and GBV. The girls were supported by social workers, psychosocial counsellors and a "mother group" to address the barriers the girls faced in continuing education. Upon the reopening of schools, all the girl beneficiaries returned to school (UNICEF, 2021, p. 24).

\section{Supporting adolescent mothers in Syria}

The Adolescent Mothers Against All Odds programme in Syria, co-developed by CARE, UNFPA and Syria Relief and Development, provides life skills and sexual and reproductive health training to adolescent girls, and works to ensure that healthcare workers provide youth-friendly, rightsbased services. In response to the pandemic, the programme was adapted to accommodate Covid-19 related restrictions on mobility and in-person gatherings. Participants were reached using WhatsApp and other remote approaches.

\section{Supporting refugees and internally displaced people with mental health issues in Zambia, Iraq, Lebanon and Bangladesh}

The UN Refugee Agency (UNHCR) recognises that many refugees have additional protection risks and need psychosocial support. An intersectional view is important in order to understand the situations of refugees who have experienced sexual and gender-based violence, have been in detention or tortured, or are unaccompanied or separated children (UNHCR, 2020). During the Covid-19 crisis, many of UNHCR and its partners' mental health and psychological support services (MHPSS) have been adapted.

In Zambia, trainers from the National Mental Health Resources Centre in Lusaka travelled to three settlements to provide on the job supervision and train participants in smaller groups with 
physical distancing and other protective measures. The training was adapted to include Covid-19 related mental health issues (UNHCR, 2020, p. 6).

In the Kurdistan region of Iraq, psychiatrists adapted their weekly clinics in camps, so that continuity of care was ensured through video psychiatric consultations with the support of camp based MHPSS staff (UNHCR, 2020, p. 6).

UNHCR in Lebanon has noted an increase in the numbers of people with specific needs seeking support. UNHCR and partners noted a deterioration of physical and mental wellbeing including an increase of documented cases of suicide by refugees and many suicide attempts as well as self-harm. UNHCR has adapted its MHPSS programming to include:

- Community messaging about coping with distress

- Training first responders in psychological first aid

- Identifying people at high risk and holding face-to-face sessions with them, while taking precautionary measures

- Strengthening community engagement and remote helping (UNHRC, 2020, pp. 12-13).

In Cox's Bazaar, Bangladesh, UNHCR supported its partners to provide MHPSS to Rohingya refugees with mental health issues. National psychologists were trained using the interagency guidance of the IASC. Then 500 community psychosocial volunteers, para counsellors and community health workers were trained in the promotion of healthy coping and maintaining psychosocial wellbeing. In addition, key messages around positive coping and Covid-19 awareness were translated into Rohingya and Bangla languages and develop audio podcasts with BBC Media (UNHCR, 2020, p. 10).

\section{A disability and gender-inclusive response to the pandemic in Zimbabwe}

As the Covid-19 pandemic spread, and its significant impact on women and girls with disabilities became apparent, UNDP Zimbabwe redesigned some of its activities to encourage an intersectional gender and disability inclusive response. In partnership with Leonard Cheshire Disability Zimbabwe, UNDP set up awareness workshops for women and girls with disabilities, caregivers and local workers. The workshops included information about the virus itself, as well as on GBV and law and policy making processes (UNDP Zimbabwe, 2020).

\section{Proposals for a feminist economic recovery plan in Hawai'i}

The Hawai'i State Commission on the Status of Women has put forward a plan for an economic recovery from Covid-19 that centres marginalised communities and people, builds social infrastructure (such as childcare, education and healthcare), and addresses the crises in healthcare, social, ecological and economic policies laid bare by the epidemic (Hawai'i State Commission on the Status of Women, 2020). Dasgupta et al. (2020) discuss the proposed plan as an example of an approach that can reimagine the "social contract" while upholding human rights and taking an intersectional approach to gender justice.

Adapting social protection programmes to include women working in informal sectors in Zambia and Kenya 
Irish Aid is supporting a number of social protection programmes that have been adapted, in the Covid-19 context, to meet the specific needs of women and girls working in informal sectors. In Zambia, a cash transfer programme for informal workers in informal setting specifically targets women. In Kenya, an emergency cash transfer programme is integrating GBV services. Also in Kenya, Trade Mark East Africa is setting up safe trading zones on the border with Uganda for women traders affected by Covid-19 (Nazneen and Araujo, 2020, p. 8).

\section{Facilitating the re-entry of adolescent mothers into education post Covid-19 in Kenya}

The government of Kenya has begun drafting new national re-entry guidelines for learners in basic education. These are anticipated to include guidance on how to facilitate the re-entry of girls who have dropped out due to early and unintended pregnancy. This will be important guidance for teachers and head teachers to have, as it is anticipated that a surge in pregnant students may follow Covid-19 school closures (KIX, 2020, p. 12).

\section{References}

Ahlenback, V. (2020). Three reasons why we need to make the COVID-19 response LGBTIQ inclusive. Social Development Direct

https://www.sddirect.org.uk/media/1898/three-reasons-why-we-need-to-make-the-covid-19response-lgbtiq-inclusive-final-002.pdf

Banerjee, D. and Nair, V. (2020). "The untold side of Covid-19": Struggle and perspectives of the sexual minorities. Journal of Psychosexual Health 2 (2) pp. 113-120

https://journals.sagepub.com/doi/abs/10.1177/2631831820939017

Banik, R., Rahman, M., Hossain, M., Sikder, T., and Gozal, D. (2020). Covid-19 pandemic and Rohingya refugees in Bangladesh: What are the major concerns? Global Public Health, 15(10), 1578-1581. https://www.tandfonline.com/doi/full/10.1080/17441692.2020.1812103

Banks, L., Davey, C., Shakespeare, T. and Kuper, H. (2021). Disability-inclusive responses to Covid-19: Lessons learnt from research on social protection in low and middle income countries. World Development 137

https://www.sciencedirect.com/science/article/pii/S0305750X20303053

Barca, V., Hebbar, M., Cote, A., Schoemaker, E., Enfield, S., Holmes, R. and Wylde, E. (2021). Inclusive information systems for social protection: Intentionally integrating gender and disability. SPACE

https://socialprotection.org/sites/default/files/publications_files/SPACE_Inclusive\%20information \%20systems\%20for\%20social\%20protection_FINAL.pdf

Birchall, J. (2020). Data and evidence on global rollback of women and girls' rights since 2016. K4D Helpdesk Report 924

https://opendocs.ids.ac.uk/opendocs/handle/20.500.12413/15886

Bowleg, L. (2020). We're not all in this together: On Covid-19, intersectionality and structural inequality. American Journal of Public Health 110 (7), pp. 917

https://ajph.aphapublications.org/doi/full/10.2105/AJPH.2020.305766 
Crenshaw, K. (1989). Demarginalising the intersection of race and sex: A Black feminist critique of antidiscrimination doctrine, feminist theory and antiracist policies. University of Chicago Legal Forum 1(8)

https://chicagounbound.uchicago.edu/cgi/viewcontent.cgi? referer=\&httpsredir=1\&article=1052\&c ontext=uclf

Dasgupta, J., Schaaf, M., Contractor, S., Banda, A., Viana, M., Kashyntseva, O. and Ruano, A. (2020). Axes of alienation: Applying an intersectional lens on the social contract during the pandemic response to protect sexual and reproductive health and rights and health. International Journal for Equity in Health 19 (130)

https://equityhealthj.biomedcentral.com/articles/10.1186/s12939-020-01245-w

Dona, G. (2021). Race, immigration and health: The Hostile Environment and public health responses to Covid-19. Ethnic and Racial Studies 44 (5) pp. 906-918

https://www.tandfonline.com/doi/abs/10.1080/01419870.2021.1881578

Dutta, M., Agarwal, D. and Sivakami, M. (2020). The invisible among the marginalised: Do gender and intersectionality matter in the Covid-19 response? Indian Journal of Medical Ethics August 2020

https://giwps.georgetown.edu/resource/the-invisible-among-the-marginalised-do-gender-andintersectionality-matter-in-the-covid-19-response/

Efange, S. and Woodroofe, J. (2020). Covid-19: A feminist response to a global pandemic, Gender and Development Network.

https://gadnetwork.org/gadn-resources/covid-19-a-feminist-response-to-a-global-pandemic

Gender Innovation Lab (2020). Supporting women throughout the coronavirus (Covid-19) emergency response and economic recovery. World Bank

https://openknowledge.worldbank.org/handle/10986/33612

Gentilini, U., Almenfi, M., Dale, P., Demarco. G. and Santos, I. (2020). Social protection and jobs responses to Covid-19: A real-time review of country measures. World Bank

http://documents1.worldbank.org/curated/en/883501588611600156/pdf/Social-Protection-andJobs-Responses-to-COVID-19-A-Real-Time-Review-of-Country-Measures-May-1-2020.pdf

Gichuna, S., Hassan, R., Sanders, T., Campbell, R., Mutonyi, M. and Mwangi, P. (2020). Access to healthcare in a time of Covid-19: Sex workers in crisis in Nairobi, Kenya. Global Public Health 15 (10) pp. 1430-1442

https://www.tandfonline.com/doi/full/10.1080/17441692.2020.1810298

Government of the Republic of South Sudan (2020). A rapid gender analysis on Covid-19. Government of the Republic of South Sudan

https://reliefweb.int/report/south-sudan/rapid-gender-analysis-covid-19-south-sudan

Haneef, C. and Kalyanpur, A. (2020). Global rapid gender analysis for Covid-19. CARE and International Rescue Committee

https://www.care-international.org/files/files/Global_RGA_COVID_RDM_3_31_20_FINAL.pdf

Hankivsky, O. and Kapilashrami, A. (2020). Beyond sex and gender analysis: an intersectional view of the Covid-19 pandemic outbreak and response. Queen Mary University of London 
https://www.qmul.ac.uk/gpi/publications/items/beyond-sex-and-gender-analysis-an-intersectionalview-of-the-coronavirus-pandemic.html

Hawai'i State Commission on the Status of Women (2020). Building bridges, not walking on backs: A feminist economic recovery plan for Covid-19. Hawai'i State Commission on the Status of Women

https://socialprotection.org/discover/publications/building-bridges-not-walking-backs-feministeconomic-recovery-plan-covid-19

Hearle, C. and Chaturvedi, S. (2020). Implications of Covid-19 on women informal workers. WOW Helpdesk

https://assets.publishing.service.gov.uk/government/uploads/system/uploads/attachment_data/fil e/911533/Query-53-covid-and-women-informal-workers.pdf

Herbert, S. and Marquette, H. (2021). COVID-19, governance and conflict: emerging impacts and future evidence needs. K4D Emerging Issues Report 34. Institute of Development Studies https://opendocs.ids.ac.uk/opendocs/handle/20.500.12413/16477

Holmes, R., Peterman, A., Sammon, E., Venton, C. and Alfers, L. (2020). Gender and inclusion in social protection responses during Covid-19. SPACE Social Protection Approaches to Covid19

https://socialprotection.org/sites/default/files/publications_files/SPACE\%20Gender\%20and\%20In clusion_20052020v1.pdf

Horn, J. (2013). Gender and Social Movements: Overview report. BRIDGE, IDS https://socialmovements.bridge.ids.ac.uk/socialmovements.bridge.ids.ac.uk/start-here/overviewreport-and-brief-bulletin.html

Hinz, K. and Zubek, I. (2020). Why the Covid-19 pandemic needs an intersectional feminist approach. Rosa Luxemburg Stiftung Blog

https://www.rosalux.de/en/news/id/42062/why-the-covid-19-pandemic-needs-an-intersectionalfeminist-approach?cHash=82963ceb141a9a3480bfe2684d6e797b

Human Rights Watch (2020). Impact of Covid-19 on children's education in Africa. Human Rights Watch

https://www.hrw.org/news/2020/08/26/impact-covid-19-childrens-education-africa\#

ILO (2021). Covid-19 and the world of work: Country policy responses. ILO online portal https://www.ilo.org/global/topics/coronavirus/regional-country/country-responses/lang-en/index.htm

Inter-Agency Working Group (IAWG) on Disability Inclusive Covid-19 Response and Recovery (2020a). Checklist for planning a disability inclusive socioeconomic response and recovery. IAWG on Disability Inclusive Covid-19 Response and Recovery https://www.un.org/sites/un2.un.org/files/disability-inclusion_checklist_socioeconomic_response_july_2020.pdf

Inter-Agency Working Group (IAWG) on Disability Inclusive Covid-19 Response and Recovery (2020b). Covid-19 response in humanitarian settings: Examples of good practices for including persons with disabilities. IAWG on Disability Inclusive Covid-19 Response and Recovery 
https://www.un.org/sites/un2.un.org/files/gip02413_covid_humanitarian_good_practice_final_web .pdf

International Disability Alliance (2020). Toward a disability-inclusive Covid-19 response: 10 recommendations from the International Disability Alliance. International Disability Alliance https://www.internationaldisabilityalliance.org/sites/default/files/ida_recommendations_for_disabili ty-inclusive_covid19_response_final.pdf

ISCG (Inter-Sector Coordination Group) Gender Hub (2020). In the shadows of the pandemic: The gendered impact of Covid-19 on Rohingya and host communities. ISCG

https://asiapacific.unwomen.org/en/digital-library/publications/2020/10/in-the-shadows-of-thepandemic

Ito, A., Wonosaputra, E. and Ono, M. (2020). Leaving no one behind: The Covid-19 crisis through the disability and gender lens. UNDESA

https://www.un.org/development/desa/dpad/publication/un-desa-policy-brief-69-leaving-no-onebehind-the-covid-19-crisis-through-the-disability-and-gender-lens/

Itcovitz, H., van Wijk, K., Swinkels, C. and Miroro, O. (2020). How Covid-19 affects inequality in Africa. INCLUDE

https://includeplatform.net/news/how-covid-19-affects-inequality-in-africa/

Juergens, F. and Galvani, F. (2020). Social protection for older people during Covid-19 and beyond. SPACE

https://socialprotection.org/sites/default/files/publications_files/Social\%20protection\%20for\%20ol der\%20people\%20during\%20COVID-19.pdf

Kimani, J., Adhiambo, J., Kasiba, R., Mwangi, P., Were, V., Mathenge, J., Macharia, P., Cholette, F., Moore, S., Shaw, S., Becker, M., Musyoki, H., Bhattacharjee, P., Moses, S., Fowke, K., McKinnon, L. and Lorway, R. (2020). The effects of Covid-19 on the health and socioeconomic security of sex workers in Nairobi, Kenya: Emerging intersections with HIV. Global Public Health 15 (70) pp. 1073-1082

https://www.tandfonline.com/doi/pdf/10.1080/17441692.2020.1770831

KIX (2020). Teacher and learner wellbeing during the Covid-19 pandemic. KIX Observatory on Covid-19 Responses

https://www.adeanet.org/sites/default/files/kix_covid-19_observatory_first_brief.pdf

Lakam, E. (2020). At the intersection of vulnerabilities: Women and girls experiencing homelessness during the global coronavirus pandemic. GIWPS

https://giwps.georgetown.edu/at-the-intersection-of-vulnerabilities-women-and-girls-experiencinghomelessness-during-the-global-coronavirus-pandemic/

Landis, D., Kalyanpur, A., Shapiro, R., Renault, L., Brown, T. and Wegs, C. (2020). Girl-driven change: Meeting the needs of adolescent girls during Covid-19 and beyond. CARE USA https://insights.careinternational.org.uk/publications/girl-driven-change-meeting-the-needs-ofadolesent-girls-during-covid-19-and-beyond

Lind, J., Roelen, K. and Sabates-Wheeler (2020). Social protection and building back better. Institute of Development Studies and Irish Aid 
https://opendocs.ids.ac.uk/opendocs/bitstream/handle/20.500.12413/15674/Social_Protection_a nd_Building_Back_Better.pdf?sequence=1\&isAllowed=y

Lokot, M. and Avakyan, Y. (2020). Intersectionality as a lens to the Covid-19 pandemic: Implications for sexual and reproductive health in development and humanitarian contexts. Sexual and Reproductive Health Matters 28 (1) pp. 40-43

https://www.tandfonline.com/doi/full/10.1080/26410397.2020.1764748

McEwen, H. (2020). Un/knowing and un/doing sexuality and gender diversity: The global anti-gender movement against SOGIE rights and academic freedom. SAIH Norwegian Students' and Academics' International Assistance Fund

https://saih.no/assets/docs/RAPPORT-2020-Web-final-version-Orban-fixed.pdf

Nazneen, S. and Araujo, S. (2020). Gender equality and building back better. Institute of Development Studies and Irish Aid

https://opendocs.ids.ac.uk/opendocs/bitstream/handle/20.500.12413/15675/Gender_Equality_an d_Building_Back_Better.pdf?sequence=1\&isAllowed=y

Outright Action International (2020). Vulnerability amplified: The impact of the Covid-19 pandemic on $L G B T I Q$ people. Outright Action International https://outrightinternational.org/content/vulnerability-amplified-impact-covid-19-pandemic-lgbtiqpeople

Pearce, E. (2020). Disability considerations in GBV programming during the Covid-19 pandemic. GBV AoR Helpdesk

https://www.sddirect.org.uk/media/1889/gbv-aor-research-query_covid-19-disability-gbv_finalversion.pdf

Plan International UK (2020). The impacts of Covid-19 on girls in crisis. Plan International https://plan-uk.org/file/the-impact-of-covid-19-on-girls-in-crisispdf-0/download?token=vTGWyPuN

Poteat, T. (2021). Navigating the storm: How to apply intersectionality to public health in times of crisis. American Journal of Public Health 111 (1) pp. 91-92

https://ajph.aphapublications.org/doi/10.2105/AJPH.2020.305944

Ramze Rezaee, J. (2020). An intersectional approach to Covid-19 she-covery. YWCA Toronto https://www.ywcatoronto.org/takeaction/additional/intersectional

RCCE Working Group (2020). Covid 19: How to include marginalised and vulnerable people in risk communication and community engagement. UN Women

https://www.unicef.org/ukraine/en/documents/covid-19-how-include-marginalized-and-vulnerablepeople-risk-communication-and-community

Rosser, EN., Morgan, R., Tan, H., Hawkins, K., Ngunjiri, A., Oyekunle, A., Schall, B., Nacif Pimenta, D., Tamaki, E., Rocha, M. and Wenham, C. (2021). How to create a gender-responsive pandemic plan: Addressing the secondary effects of Covid-19. Gender and COVID-19 Project https://www.genderandcovid-19.org/resources/how-to-create-a-gender-responsive-pandemicplan/

Ruwisi, N. (2020). Female traders in Zimbabwe. Rosa Luxemburg Stiftung

https://www.rosalux.de/en/news/id/42646/female-traders-in-

zimbabwe?cHash=a525b81d4f58577fb450e3984604c39a 
Ryan, N. and Al-Ayadi, A. (2020). A call for a gender-responsive, intersectional approach to address Covid-19. Global Public Health 15 (9) pp. 1404-1412

https://www.tandfonline.com/doi/full/10.1080/17441692.2020.1791214

Shakespeare, T., Watson, N., Brunner, R., Cullingworth, J., Hameed, S., Scherer, N., Pearson, C. and Reichenberger, V. (2021). Disabled people in Britain and the impact of the Covid-19 pandemic

https://www.preprints.org/manuscript/202101.0563/v1

Tariq, F. and Bibler, S. (2020). Gender impact of Covid-19 in Pakistan: Contextual analysis and the way forward. International Foundation for Electoral Systems https://www.ifes.org/sites/default/files/gender_impact_of_covid19_in_pakistan_contextual_analysis_and_the_way_forward_may_2020.pdf

TDR (2020). Incorporating intersectional gender analysis into research on infectious diseases of poverty: A toolkit for health researchers. World Health Organisation

http://tdr-intersectional-gender-toolkit.org/cover/0001.html?target=_self\&lightbox=0

UNDP (2020). Impact of the Covid-19 pandemic on family planning and ending gender-based violence, female genital mutilation and child marriage. UNDP https://www.unfpa.org/sites/default/files/resource-pdf/COVID19_impact_brief_for_UNFPA_24_April_2020_1.pdf

UNDP Zimbabwe (2020). Covid-19 and persons with disabilities: Leaving no one behind. UNDP Zimbabwe

https://www.zw.undp.org/content/zimbabwe/en/home/presscenter/articles/covid19-and-personswith-disabilities--leaving-no-one-behind-.html

UNHCR (2020). Emerging practices: Mental health and psychosocial support in refugee operations during the Covid-19 pandemic. UNHCR https://www.unhcr.org/5ee2409b4.pdf

UNICEF (2021). Reimagining girls' education: Solutions to keep girls learning in emergencies. UNICEF

https://www.unicef.org/reports/reimagining-girls-education

United Nations (2020). A disability-inclusive response to Covid-19. United Nations

https://www.un.org/sites/un2.un.org/files/sg_policy_brief_on_persons_with_disabilities_final.pdf

UNPRPD (2020a). Initial overview of specific social protection measures for persons with disabilities and their families in response to the Covid-19 crisis. UNPRPD

http://unprpd.org/sites/default/files/Overview\%20response_1.4.pdf

UNPRPD (2020b). Disability inclusive social protection response to Covid-19 crisis. UNPRPD, ILO, International Disability Alliance, UNICEF and Embracing Diversity https://www.social-protection.org/gimi/gess/RessourcePDF.action;jsessionid=q-I60qp8--bOf_iAsphKwXEL58naMIlsQ1gWreV6Z0xh_dAtnZF!-2033066120?id=56029

UN Women (2020a). Women with disabilities in a pandemic (Covid-19). Country support policy brief 1. UN Women

https://www.unwomen.org/en/digital-library/publications/2020/04/policy-brief-women-withdisabilities-in-a-pandemic-covid-19 
UN Women (2020b). Gender-responsive humanitarian life-saving response to the Covid-19 pandemic: Saving lives, reducing impact and building resilience. UN Women

https://www.unwomen.org/en/digital-library/publications/2020/07/proposal-gender-responsivehumanitarian-response-to-the-covid-19-pandemic

UN Women (2020c). Covid-19 Bangladesh rapid gender analysis. UN Women

https://asiapacific.unwomen.org/en/digital-library/publications/2020/05/covid-19-bangladesh-

rapid-gender-analysis

UN Women (2020d). Priorities for gender equality in Yemen's Covid-19 response. UN Women https://arabstates.unwomen.org/en/digital-library/publications/2020/05/brief-priorities-for-genderequality-in-yemen-covid19-response

UN Women (2020e). The shadow pandemic: Violence against women during Covid-19. UN Women

https://www.unwomen.org/en/news/in-focus/in-focus-gender-equality-in-covid-19-

response/violence-against-women-during-covid-19

UN Women (2020f). Covid-19 and ending violence against women and girls. UN Women https://www.unwomen.org/-

/media/headquarters/attachments/sections/library/publications/2020/issue-brief-covid-19-andending-violence-against-women-and-girls-en.pdf?la=en\&vs=5006

UN Women, International Rescue Committee and Roshan (2020). Unlocking the lockdown: Gender differentiated consequences of Covid-19 in Afghanistan. UN Women, International Rescue Committee, Roshan and Women Count

https://reliefweb.int/report/afghanistan/unlocking-lockdown-gender-differentiated-consequencescovid-19-afghanistan

Women Enabled International (2020a). Statement on rights at the intersection of gender and disability during Covid-19. Women Enabled International

https://womenenabled.org/blog/statement-on-covid-19-for-endorsement/

Women Enabled International (2020b). Covid-19 at the intersection of gender and disability: Findings of a global human rights survey, March to April 2020. Women Enabled International https://womenenabled.org/pdfs/Women\%20Enabled\%20International\%20COVID19\%20at\%20the \%20Intersection\%20of\%20Gender\%20and\%20Disability $\% 20$ May $\% 202020 \% 20$ Final.pdf 


\section{Acknowledgements}

We thank the following experts who voluntarily provided suggestions for relevant literature or other advice to the author to support the preparation of this report. The content of the report does not necessarily reflect the opinions of any of the experts consulted.

- Sian Herbert, K4D and GSDRC

- Amanda McRae, Women Enabled International

- Rebecca Holmes, ODI

- Emma Lovell, ODI

- Andrew Shepherd, ODI

- Tom Shakespeare, London School of Hygiene and Tropical Medicine

\section{Suggested citation}

Birchall, J. (2021) Intersectionality and Responses to Covid-19, Covid Collective Helpdesk Report 3, Brighton: Institute of Development Studies, DOI: 10.19088/ CC.2021.003

\section{About this report}

This report is based on 5 days of desk-based research. The Covid Collective research helpdesk provides rapid syntheses of a selection of recent relevant literature and international expert thinking in response to specific questions relating to international development. For any enquiries, contact Covid Collective- covidcollective@ids.ac.uk.

This evidence summary was funded by the UK Government's Foreign, Commonwealth and Development Office (FCDO) through the Covid Collective. It is licensed for non-commercial purposes only. Except where otherwise stated, it is licensed for non-commercial purposes under the terms of the Open Government Licence v3.0. Covid Collective cannot be held responsible for errors, omissions or any consequences arising from the use of information contained. Any views and opinions expressed do not necessarily reflect those of FCDO, Covid Collective or any other contributing organisation.

(c) Crown copyright 2027 . 